\title{
Quality assurance in radiotherapy: analysis of the causes of not starting or early radiotherapy withdrawal
}

\author{
Meritxell Arenas ${ }^{*}$, Sebastià Sabater ${ }^{2}$, Marina Gascón ${ }^{1}$, Ivan Henríquez ${ }^{1}$, M José Bueno ${ }^{3}$, Àngels Rius ${ }^{4}$, \\ Àngels Rovirosa ${ }^{5}$, David Gómez', Anna Lafuerza', Albert Biete ${ }^{5}$ and Jordi Colomer ${ }^{6}$
}

\begin{abstract}
Background: The aim of this study was to analyse the reasons for not starting or for early of radiotherapy at the Radiation Oncology Department.

Methods: All radiotherapy treatments from March 2010 to February 2012 were included. Early withdrawals from treatment those that never started recorded. Clinical, demographic and dosimetric variables were also noted.

Results: From a total of 3250 patients treated and reviewed, 121 (4\%) did not start or complete the planned treatment. Of those, 63 (52\%) did not receive any radiotherapy fraction and 58 (48\%) did not complete the course, $74 \%$ were male and $26 \%$ were female. The mean age was $67 \pm 13$ years. The most common primary tumour was lung (28\%), followed by rectum (16\%). The aim of treatment was $62 \%$ radical and $38 \%$ palliative, $44 \%$ of patients had metastases; the most common metastatic site was bone, followed by brain. In 38\% of cases (46 patients) radiotherapy was administered concomitantly with chemotherapy (10 cases (22\%) were rectal cancers).

The most common reason for not beginning or for early withdrawal of treatment was clinical progression (58/121, 48\%). Of those, $43 \%$ died (52/121), 35 of them because of the progression of the disease and 17 from other causes. Incomplete treatment regimens were due to toxicity (12/121 (10\%), of which 10 patients underwent concomitant chemotherapy for rectal cancer).

Conclusions: The number of patients who did not complete their course of treatment is low, which shows good judgement in indications and patient selection. The most common reason for incomplete treatments was clinical progression. Rectal cancer treated with concomitant chemotherapy was the most frequent reason of the interruption of radiotherapy for toxicity.
\end{abstract}

Keywords: Quality assurance, Radiotherapy, Not starting treatments, Early withdrawal treatments

\section{Background}

The province of Tarragona in the south of Catalonia, Spain, has a total area of $6303 \mathrm{Km}^{2}$ and a total population over 800000 inhabitants. The Radiation Oncology Department of Hospital Universitari Sant Joan de Reus attends to all the candidates for radiotherapy (RT) in the entire province, and is a centre of reference for the Tarragona province.

\footnotetext{
* Correspondence: meritxell.arenas@gmail.com

'Department of Radiation Oncology, Hospital Universitari Sant Joan de Reus, Institut d'Investigacions Sanitàries Pere Virgili (IISPV), Universitat Rovira i Virgili (URV), Tarragona, Spain

Full list of author information is available at the end of the article
}

Quality assurance in health care has become more and more important in recent years. Several papers have been published on quality control in RT [1-6]. Our department has great interest in quality assurance and has put an enormous effort into its quality assurance programme. In 2000, a quality assurance system project based on the so-called International Organization for Standardizations (ISO) 9001 Quality Standards was started. One of the standards applied in our quality assurance system was the number of patients with incomplete treatments.

The aim of this study is to analyse the reasons for incomplete treatments at the Radiation Oncology Department.

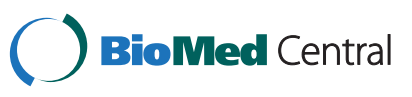

(c) 2014 Arenas et al.; licensee BioMed Central Ltd. This is an Open Access article distributed under the terms of the Creative Commons Attribution License (http://creativecommons.org/licenses/by/4.0), which permits unrestricted use, distribution, and reproduction in any medium, provided the original work is properly credited. The Creative Commons Public Domain Dedication waiver (http://creativecommons.org/publicdomain/zero/1.0/) applies to the data made available in this article, unless otherwise stated. 


\section{Methods}

All treatments carried out at the Radiation Oncology Department over a two-year period (from March 2010 until February 2012) were reviewed. Early withdrawals and those patients that never started treatment were recorded. Information regarding patients, demographic characteristics, disease, treatment characteristics and dosimetric variables were collected retrospectively from the patients' records.

Our department receives patients for RT treatments from different specialists from seven hospitals in the province. We have a hospitalisation area where the patients' who need care are attended. Patients are admitted for symptom control, for disease progression or for toxicity treatment.

The planning process for RT includes the first consultation including collecting the clinical history and examination of the patient. In this first consultation the clinician explains the aim of treatment and its procedures and informs patients and their families of the benefits and any acute and/or late side effects they might expect and patients sign the treatment consent form. That same day, if the indicated treatment proceeds, the clinical decides the position and immobilization of the patient simulation and the acquisition of $\mathrm{CT}$ simulation. Then we proceed to the prescription dose treatment and delineation of tumour volumes and organs at risk, in order to make the corresponding 3D dosimetry. Then we review dosimetry, the treatment volumes as well as histograms of the organs at risk. If treatment is accepted, the patient starts treatment in the unit prior to performing verification.

The RT indication, radical vs. palliative, as well as the need of a concomitant chemotherapy course is evaluated by the attending clinician after assessment of general conditions and co-morbidities of the patients. During treatment, patients are scheduled for regular visits.

In our review, patients had been treated by standard techniques at normo- or hypofractionation (1.8-8 Gy/ day) 5 days/week with a variety of equipment including 6-18 MV photons and/or 6-20 MeV electrons from the linear accelerator. Our Department has 4 linear accelerators, 1 ortho-voltage, and a high-dose brachytherapy programme. All treatment planning was done in 3D.

In this study, we define incomplete treatment as a patient who has undergone at least one simulation/planning procedure prior to starting an RT course; early withdrawal means that a patient has received some irradiation treatment fraction but failed to complete the scheduled course; a non-starting patient is defined as one who did not receive even a single fraction of radiation after the simulation and planning. A compliant patient is therefore defined as a patient who was able to complete the course of radiation as intended.

\section{Statistical analysis}

The results are shown as medians ( \pm standard deviations). Chi-square test was used to compare categorical variables. Two-sided t-test was used to determine differences in continuous variables. In the logistic regression model, we included all predictor variables in the univariate analysis. Values of $\mathrm{p}<0.05$ were considered significant.

\section{Results}

A total of 3250 patients were treated during the analysed period, RT was indicated (most frequent first) to treat breast cancer ( $\mathrm{n}=748$ patients, $23 \%$ ), to improve symptoms $(\mathrm{n}=715,22 \%)$, to treat prostate cancer $(\mathrm{n}=585$, $18 \%)$, and to treat rectal cancer $(\mathrm{n}=221,7 \%)$.

Table 1 shows patient characteristics of all incomplete treatments. It shows that $121 / 3250$ patients (4\%) were incomplete treatments. Of those, 63/121 (52\%) did not receive any therapy fraction and the other 58/121 (48\%) did not complete the scheduled course, $74 \%$ of them were male and $26 \%$ were female. The mean age was $67 \pm$ 13 years. Mean distance from home to Department was $11 \pm 16 \mathrm{Km}$. Fifty-eight percent of the patients travelled to the Department by ambulance and $27 \%$ of them were in-patients. The most common primary tumour location was the lung $(28 \%)$, followed by the rectum $(16 \%)$. The aim of treatment was radical in $62 \%$ and palliative in $38 \%$ of cases. Metastases were evident in $44 \%$ of the patients. The most common metastatic site was bone, followed by brain. In $38 \%$ of cases (46/121 patients) RT was administered concomitantly with chemotherapy (10/121 cases (22\%) were rectal cancers).

Mean time to the beginning of treatment was $7 \pm 4$ days. Mean planned dose was $47 \pm 18$ Gy. Mean sessions scheduled $22 \pm 12$ Gy. Early withdrawal median dose $12 \pm 17$ Gy. Clinical progression was the most frequent reason for incomplete courses $(58 / 121,48 \%)$. Patient death was the cause of incomplete courses in 52 patients (43\%), 35 of them due to clinical progression and 17 from other causes. Toxicity was responsible for incompleteness in 10\% (12/ 121) of patients, ten of them being rectal cancer patients treated with concomitant chemotherapy.

Table 2 compares the characteristics between to nonstarting patients and early withdrawal patients.

We compared the non-compliant irradiation group with the patients that finished their planned RT course. Men were more frequently associated with non-compliant irradiation courses $(5 \%)$ than women $(2 \%)(\mathrm{p}<0.005)$. A slightly advanced age was significantly associated with non-compliance (non-compliant courses, $67 \pm 13$ years, completed courses, $65 \pm 13$ years). Palliative patients were significantly more non-compliant than non-palliative patients $(6 \%$ vs. $3 \% ; \mathrm{p}<0.005)$ but palliative patients were slightly significantly younger ( $64 \pm 13$ years) than radical patients $(65 \pm 13$ years $)(p=0.049)$. There was a significant 
Table 1 Patient characteristics of all incomplete treatments

\begin{tabular}{|c|c|c|c|}
\hline & & $\mathrm{N}$ & $\%$ \\
\hline \multirow[t]{2}{*}{ Sex } & Male & 89 & 74 \\
\hline & Female & 32 & 26 \\
\hline \multirow[t]{4}{*}{ Tumour location } & Lung & 34 & 28 \\
\hline & Rectum & 19 & 16 \\
\hline & Skin & 14 & 12 \\
\hline & Other & 54 & 45 \\
\hline \multirow[t]{2}{*}{ Metastasis } & Yes & 41 & 34 \\
\hline & No & 80 & 66 \\
\hline \multirow[t]{2}{*}{ Palliative } & Yes & 46 & 38 \\
\hline & No & 75 & 62 \\
\hline \multirow{2}{*}{$\begin{array}{l}\text { Concomitant } \\
\text { chemotherapy }\end{array}$} & Yes & 46 & 38 \\
\hline & No & 75 & 62 \\
\hline \multirow[t]{2}{*}{ Ambulance } & Yes & 70 & 58 \\
\hline & No & 51 & 42 \\
\hline \multirow[t]{2}{*}{ Inpatient } & Yes & 33 & 27 \\
\hline & No & 88 & 73 \\
\hline \multirow[t]{2}{*}{ Type of early withdrawal } & Incomplete course & 58 & 48 \\
\hline & Any fraction & 63 & 52 \\
\hline \multirow[t]{7}{*}{ Reason for withdrawal } & Death due to tumour progression & 35 & 29 \\
\hline & Clinical progression & 23 & 19 \\
\hline & $\begin{array}{l}\text { Death due to non-oncology } \\
\text { reasons }\end{array}$ & 17 & 14 \\
\hline & Toxicity & 12 & 10 \\
\hline & Patient refusal & 10 & 8 \\
\hline & Dosimetric issues & 5 & 4 \\
\hline & Other & 19 & 16 \\
\hline
\end{tabular}

association between the primary tumour location and noncompliance; the main locations were brain (10\% of them), lung ( $8 \%$ of them), rectum ( $7 \%$ of them) and head and neck $(6 \%)(\mathrm{p}<0.005)$. Despite that, a palliative course was associated with bladder ( $59 \%$ of them), lung ( $58 \%$ of them), rectum $(17 \%$ of them), and breast $(15 \%$ of them) $(\mathrm{p}<0.005)$.

No significant differences in the planned dose were evident between patients who completed their irradiation course ( $48 \pm 21 \mathrm{~Gy})$ and those non-compliant ( $47 \pm 18 \mathrm{~Gy}$ ). Mean dose in the non-compliant course group, $12 \pm 17 \mathrm{~Gy}$. No significant differences between non-starting patients and early withdrawal patients were evident according to the age, sex, location of the primary tumour, or planned dose.

Table 3 summarizes the results of the logistic regression analysis for predictors of non-compliance among all patients. Age, ambulance usage and primary tumour location were significant. Sex and type of RT course were not predictive of treatment discontinuation in the multivariate analysis.

\section{Discussion}

Radiation treatment is a complex procedure because it requires highly specialized equipment and technology as well as trained professionals.

Both the patient-related aspects (diagnosis, selection, treatment indication, justification, referral, planning, therapy, and follow-up) and the control and measurement procedures that form the technical part of the treatment process should be subject to regular planning, verification and, mostly, constant improvement $[7,8]$.

In this study, we focus on incompleteness of radiation courses due to the well-established connection between cancer treatment compliance and its outcomes [9-11]. A correct evaluation of the parameters involved in noncompliance has consequences, not only when selecting patients for a radical/palliative treatment, but also when planning RT resources and saving costs. The causes of non-compliance to a prescribed treatment could be a good quality indicator for an RT department because they can show the accuracy of selection when prescribing irradiation.

Interruptions during the course of treatment include planned unit maintenance and servicing, acute patient toxicity and unexpected malfunction of linear accelerators. Toxicity increases alongside concomitant chemoradiotherapy schedules. As far as we know, there are no similar global studies published that have analysed early withdrawal and non-starting irradiation factors in the RT domain. Studies have focused on oncological noncompliance treatments, analysing chemotherapy or hormonal therapy or RT in a specific context. Some of the most common topics are breast cancer [12-16] or head and neck cancer $[17,18]$ and insurance status $[13,14,17-20]$, which is related with the hospital type or about elderly patients $[16,18,21]$. A global study directed at analysing the duration of curative RT has also been published [22], but it was aimed at evaluating ways to counteract short RT interruptions, such as those caused by public holidays or machine maintenance. Some factors associated with treatment interruptions or early withdrawal, described in these published studies, especially those related with health insurance or financial issues, could not be included in our study due to the big differences between the Spanish and American Health Systems and the population sizes.

No irradiation compliance, as defined in the present study, was very low (4\%), the main causes being clinical progression (48\%) and death due to non-oncology reasons. Male patients were more frequently non-compliant in palliative treatments. Despite results showing a significant slightly younger age for non-compliant patients, 
Table 2 Characteristics of non-starting patients and early withdrawn patients

\begin{tabular}{|c|c|c|c|c|c|c|}
\hline & & Non-starting & & Early withdrawal & & \\
\hline & & $\mathrm{N}$ & $\%$ & $\mathrm{~N}$ & $\%$ & \\
\hline \multirow[t]{2}{*}{ Sex } & Male & 50 & 79 & 39 & 67 & 0.131 \\
\hline & Female & 13 & 21 & 19 & 33 & \\
\hline \multirow[t]{4}{*}{ Tumour location } & Lung & 21 & 33 & 13 & 22 & 0.045 \\
\hline & Rectum & 4 & 6 & 15 & 26 & \\
\hline & Skin & 5 & 8 & 9 & 16 & \\
\hline & Other & 33 & 52 & 21 & 36 & \\
\hline \multirow[t]{2}{*}{ Metastasis } & Yes & 16 & 25 & 25 & 43 & 0.04 \\
\hline & No & 47 & 75 & 33 & 57 & \\
\hline \multirow[t]{2}{*}{ Palliative } & Yes & 19 & 30 & 27 & 47 & 0.063 \\
\hline & No & 44 & 70 & 31 & 53 & \\
\hline \multirow[t]{2}{*}{ Concomitant chemotherapy } & Yes & 21 & 33 & 25 & 43 & 0.269 \\
\hline & No & 42 & 67 & 33 & 57 & \\
\hline \multirow[t]{2}{*}{ Ambulance } & Yes & 30 & 48 & 40 & 69 & 0.022 \\
\hline & No & 32 & 52 & 18 & 31 & \\
\hline \multirow[t]{2}{*}{ Inpatient } & Yes & 12 & 19 & 21 & 36 & 0.034 \\
\hline & No & 51 & 81 & 37 & 64 & \\
\hline \multirow[t]{7}{*}{ Reason for withdrawal } & Death due to tumour progression & 17 & 27 & 18 & 31 & \\
\hline & Clinical progression & 8 & 13 & 15 & 26 & \\
\hline & Non-oncology reasons & 6 & 10 & 11 & 19 & 0.001 \\
\hline & Toxicity & 2 & 3 & 8 & 14 & \\
\hline & Patient refusal & 10 & 16 & 2 & 3 & \\
\hline & Dosimetric issues & 5 & 8 & 0 & 0 & \\
\hline & Other & 15 & 24 & 4 & 7 & \\
\hline
\end{tabular}

Table 3 Multivariate logistic regression for predictors of lack of treatment compliance among all patients

\begin{tabular}{|c|c|c|c|c|}
\hline & B & $\operatorname{Exp}(B)$ & $95 \% \mathrm{Cl}$ & Sig. \\
\hline RT course (radical) & .354 & 1.424 & $.913-2.222$ & .119 \\
\hline Age & -.021 & .980 & $.964-.996$ & .013 \\
\hline Ambulance use & -.982 & .374 & $.256-.547$ & .000 \\
\hline Sex (female) & .245 & 1.278 & $.783-2.085$ & .326 \\
\hline \multicolumn{4}{|l|}{ Primary location } & .000 \\
\hline Bladder & 1.499 & 4.478 & $1.285-15.605$ & .019 \\
\hline Head \& neck & .345 & 1.412 & $.655-3.044$ & .378 \\
\hline Skin & 1.837 & 6.276 & $2.475-15.913$ & .000 \\
\hline Breast & 1.992 & 7.329 & $2.977-18.046$ & .000 \\
\hline Lung & .252 & 1.287 & $.713-2.323$ & .403 \\
\hline Rectum & .289 & 1.335 & $.662-2.693$ & .420 \\
\hline Lymphoma & 1.190 & 3.287 & $.732-14.751$ & .120 \\
\hline Prostate & 2.256 & 9.546 & $3.834-23.764$ & .000 \\
\hline Gynaecological & 18.517 & 110098206.961 & $.000-$ & .99 \\
\hline CNS & -.165 & .847 & $.329-2.185$ & .732 \\
\hline
\end{tabular}

RT: radiotherapy; CNS: Central nervous system; 95\% Cl: 95\% confidence interval. the difference has no clinical relevance but is explained by a the younger age of palliative patients. This is an important finding because some studies have associated advanced age with lower frequency of definitive or adequate cancer treatment in some studies $[23,24]$ even though other studies suggest that older patients can benefit similarly to younger patients $[25,26]$ with high rates of irradiation completion $[16,18,21]$. It is important to keep one's mind on carrying out an accurate comprehensive geriatric assessment because there is a possibility of declining functional status [27] or even an early death [28] due to cancer treatment in older patients.

Not surprisingly, patients with brain cancer or lung cancer were more frequently non-compliant. A previous report from our group showed a $27 \%$ early withdrawal from RT among brain metastasis patients [29] stressing the need for an accurate patient selection in order to avoid overtreatment. Obviously the current study, which involves curative and palliative patients, shows lower figures, with a $4 \%$ overall incidence of non-compliance. It should be noted that concomitant chemotherapy for rectal cancer was the most frequent reason for non-compliance due to toxicity, nearly half of them by concomitant capecitabine, 
despite different studies showing that the replacement of 5 -FU by oral capecitabine in concurrent treatment of locally advanced rectal cancer with RT is generally welltolerated and effective [30-34]. Interestingly, we found that the mean time for beginning treatment was $7 \pm 4$ days, so the results presented here do not reflect delays due to the health care system or waiting lists.

The main limitation of our study is the lack of additional socio-economic or clinical data that might be useful for designing preventive policies that avoid irradiation discontinuation. Policies directed at predicting, correcting and preventing treatment interruptions, including integrated oncology care pathways, would reduce treatment variations and improve quality of patient care and compliance with guidelines [35]. Central review systems that have demonstrated an increase in CTV delineation [36] could be expanded to clinical areas. In spite of finding a slightly younger age associated with non-compliance, there is a need for a comprehensive geriatric assessment because it has shown to improve elderly cancer patient care. A successful implementation of such measures would result in improved patient outcome as well as a more economical usage of resources.

\section{Conclusions}

This is the first study to our knowledge that reports the incidence and the reasons for incomplete irradiation courses. The overall number of non-compliant of patients is low, showing good judgement in treatment and patient selection.

The most frequent reason for incomplete treatment was clinical progression. Toxicity during a rectal cancer treatment, with concomitant chemotherapy, was the most frequent reason for the interruption of curative courses.

\section{Summary}

The reasons for not starting or early withdrawal of radiotherapy are normally clinical and are not well established. We analysed the patients who did not start radiotherapy or who withdrew early at the Radiation Oncology Department of University Hospital over a two year period. We observed that the most common reason was clinical progression. Rectal cancer treated with concomitant chemotherapy was the most frequent reason for the radiotherapy to be interrupted due to toxicity.

\section{Competing interests}

The authors declare that they have no competing interest.

\section{Authors' contributions}

MA and SS are lead authors who participated in manuscript drafting, tables creation and manuscript revision. $M G, I H, M B, A R, D G, A L, A B$ and JC provided patient data. All authors read, revised and approved the final manuscript.

\section{Acknowledgements}

We would like to thank Pilar Hernández for her support with the statistical analysis and Jordi Trilla, Yolanda López, Mauricio Murcia, Monica Arguis, Alida Pardo, Lorena Diez for their help with the treatment of the patients.

\section{Author details}

${ }^{1}$ Department of Radiation Oncology, Hospital Universitari Sant Joan de Reus, Institut d'Investigacions Sanitàries Pere Virgili (IISPV), Universitat Rovira i Virgili (URV), Tarragona, Spain. ${ }^{2}$ Department of Radiation Oncology, Complejo Hospitalario Universitario de Albacete, Albacete, Spain. ${ }^{3}$ Department of Quality, Hospital Universitari Sant Joan de Reus, Tarragona, Spain.

${ }^{4}$ Department of Statistics, Hospital Universitari Sant Joan de Reus, Tarragona, Spain. ${ }^{5}$ Department of Radiation Oncology, Hospital Universitari Clínic de Barcelona, Barcelona, Spain. ${ }^{6}$ Hospital Universitari Sant Joan de Reus and Group SAGESSA (Assistència Sanitària i Social), Tarragona, Spain.

Received: 4 July 2014 Accepted: 12 November 2014

Published online: 04 December 2014

\section{References}

1. Horiot JC, Bernier J, Johansson KA, van der Schueren E, Bartelink H: Minimum requirements for quality assurance in radiotherapy. Radiother Oncol 1993, 29(2):103-104.

2. Horiot JC, van der Schueren E, Johansson KA, Bernier J, Bartelink H: The programme of quality assurance of the EORTC radiotherapy group. A historical overview. Radiother Oncol 1993, 29(2):81-84.

3. Van Dam J, Johansson KA, Bridier A, Sernbo G, Hansson U: EORTC radiotherapy group quality assurance: mechanical checks and beam alignments of megavoltage equipment. Radiother Oncol 1993, 29(2):91-96.

4. Leer JW, Corver R, Kraus JJ, vdTogt JC, Buruma OJ: A quality assurance system based on ISO standards: experience in a radiotherapy department. Radiother Oncol 1995, 35(1):75-81.

5. Valentini V, Glimelius B, Frascino V: Quality assurance and quality control for radiotherapy/medical oncology in Europe: Guideline development and implementation. Eur J Surg Oncol 2013, 39(9):938-944.

6. Taghavi Bayat B, Gill S, Siva S, Tai KH, Joon ML, Foroudi F: Ten-year results of quality assurance in radiotherapy chart round. BMC Health Serv Res 2013, 23(13):148

7. Bogusz-Czerniewicz M: Quality management system in radiotherapy in the light of regulations applicable in Poland. Contemp Oncol (Pozn) 2012, 16(2):140-146.

8. Bogusz-Czerniewicz M: Clinical quality standards for radiotherapy. Contemp Oncol (Pozn) 2012, 16(1):44-52.

9. Hershman DL, Shao T, Kushi LH, Buono D, Tsai WY, Fehrenbacher L, Kwan M, Gomez SL, Neugut Al: Early discontinuation and non-adherence to adjuvant hormonal therapy are associated with increased mortality in women with breast cancer. Breast Cancer Res Treat 2011, 126(2):529-537.

10. Patel MR, Deal AM, Shockley WW: Oral and plunging ranulas: What is the most effective treatment? Laryngoscope 2009, 119(8):1501-1509.

11. Badakhshi H, Gruen A, Sehouli J, Budach V, Boehmer D: The impact of patient compliance with adjuvant radiotherapy: a comprehensive cohort study. Cancer med 2013, 2(5):712-717.

12. Hershman DL, Kushi LH, Shao T, Buono D, Kershenbaum A, Tsai WY, Fehrenbacher L, Gomez SL, Miles S, Neugut Al: Early discontinuation and nonadherence to adjuvant hormonal therapy in a cohort of 8769 early-stage breast cancer patients. J Clin Oncol 2010, 28(27):4120-4128.

13. Sedjo RL, Devine S: Predictors of non-adherence to aromatase inhibitors among commercially insured women with breast cancer. Breast Cancer Res Treat 2011, 125:192-200.

14. Ramsey SD, Zeliadt SB, Richardson LC, Pollack LA, Linden H, Blough DK, Moinpour CM, Hall IJ, Smith JL, Ekwueme DU, Fairweather ME, Thompson $I M$, Keane TE, Penson DF: Discontinuation of radiation treatment among Medicaid-enrolled women with local and regional stage breast cancer. Breast J 2010, 16(1):20-27.

15. Fontein DBY, Nortier JWR, Liefers GJ, Putter H, Meershoek-Klein Kranenbarg E, Van den Bosch J: High non-compliance in the use of letrozole after 2.5 years of extended adjuvant endocrine therapy. Results from IDEAL randomized trial. Eur J Surg Oncol 2012, 38(2):110-117.

16. Fiorica F, Berretta M, Ursino S, Fisichella R, Lleshi A, Fiorica G, Stefanelli A, Zini G, Tirelli U, Zanghi A, Cappellani A, Berretta S, Cartei F: Adjuvant radiotherapy on older and oldest breast cancer patients after 
conservative surgery: a retrospective analysis. Arch Gerontol Geriatr 2012, 55(2):283-288.

17. Fesinmeyer MD, Mehta V, Tock L, Blough D, McDermott C, Ramsey SD: Completion of radiotherapy for local and regional head and neck cancer in medicare. Arch Otolaryngol Head Neck Surg 2009, 135(9):860-867.

18. Sharma A, Madan R, Kumar R, Sagar P, Kamal VK, Thakar A, Sharma A, Mohanti BK: Compliance to therapy-elderly head and neck carcinoma patients. Can Geriatr J 2014, 17(3):83-87.

19. Neugut Al, Subar M, Wilde ET, Stratton S, Brouse CH, Hillyer GC, Grann VR, Hershman DL: Association between prescription co-payment amount and compliance with adjuvant hormonal therapy in women with early-stage breast cancer. J Clin Oncol 2011, 29(18):1534-1542.

20. Sheti RA, Stamell EF, Price L, DeLacure M, Sanfilippo N: Head and neck radiotherapy compliance in an underserved patient population. Laryngoscope 2010, 120(7):1336-1341.

21. Fiorica F, Cartei F, Carau B, Berretta M, Spartà D, Tirelli U, Santangelo A, Maugeri D, Luca S, Leotta C, Sorace R, Berretta M: Adjuvant radiotherapy on older and oldest elderly rectal cancer patients. Arch Gerontol Geriatr 2009, 49(1):54-59.

22. Maciá Garau M, Solé Monné J, Cambra Serés MJ, Monfà Binefa C, Peraire LM: Compliance to the prescribed overall treatment time (OTT) of curative radiotherapy in normal clinical practice and impact on treatment duration of counteracting short interruptions by treating patients on Saturdays. ClinTransl Oncol 2009, 11(5):302-311.

23. Enger SM, Thwin SS, Buist DS, Field T, Frost F, Geiger AM, Lash TL, Prout M, Yood MU, Wei F, Silliman RA: Breast cancer treatment of older women in integrated health care settings. J Clin Oncol 2006, 24(27):4377-4383.

24. Owonikoko TK, Ragin CC, Belani CP, Oton AB, Gooding WE, Taiolo E, Ramalingam SS: Lung cancer in elderly patients: an analysis of the surveillance epidemiology, and end results database. J Clin Oncol 2007, 25(35):5570-5577

25. Sargent DJ, Goldberg RM, Jacobson SD, Macdonald JS, Labianca R, Haller DG, Shepherd LE, Seitz JF, Francini G: A pooled analysis of adjuvant chemotherapy for resected colon cancer in elderly patients. N Engl J Med 2001, 345(15):1091-1097.

26. Muss HB, Berry DA, Cirrincione C, Budman DR, Henderson IC, Citron ML, Norton L, Winer EP, Hudis CA, Cancer and Leukemia Group B Experience: Toxicity of older and younger patients treated with adjuvant chemotherapy for node-positive breast cancer: the Cancer and Leukemia Group B Experience. J Clin Oncol 2007, 25(24):3699-3704.

27. Hoppe S, Rainfray M, Fonck M, Hoppenreys L, Blanc JF, Ceccaldi J, Mertens C, Blanc-Bisson C, Imbert Y, Cany L, Vogt L, Dauba J, Houédé N, Bellera CA, Floquet A, Fabry MN, Ravaud A, Chakiba C, Mathoulin-Pélissier S, Soubeyran $P$ : Functional decline in older patients with cancer receiving first-line chemotherapy. J Clin Oncol 2013, 31(31):3877-3882.

28. Soubeyran P, Fonck M, Blanc-Bisson C, Blanc JF, Ceccaldi J, Mertens C, Imbert Y, Cany L, Vogt L, Dauba J, Andriamampionona F, Houédé N, Floquet A, Chomy F, Brouste V, Ravaud A, Bellera C, Rainfray M: Predictors of early death risk in older patients treated with first-line chemotherapy for cancer. J Clin Oncol 2012, 30(15):1829-1834.

29. Sabater S, Mur E, Müller K, Arenas M: Predicting compliance and survival in palliative whole-brain radiotherapy for brain metastases. Clin Trans/ Oncol 2012, 14:43-49.

30. Sauer R, Becker H, Hohenberger W, Rödel C, Wittekind C, Fietkau R, Martus P, Tschmelitsch J, Hager E, Hess CF, Karstens JH, Liersch T, Schmidberger H, Raab R, German Rectal Cancer Study Group: Preoperative versus - chemoradiotherapy for rectal cncer. N Engl J Med 2004, 351(17):1731-1740.

31. Velenik V, Oblak I, Anderluh F: Long-term results from a randomized phase II trial of neoadjuvant combined-modality therapy for locally advanced rectal cancer. Radiat Oncol 2010, 5:88.

32. O'Connell MJ, Colangelo LH, Beart RW, Petrelli NJ, Allegra CJ, Sharif S, Pitot HC, Shields AF, Landry JC, Ryan DP, Parda DS, Mohiuddin M, Arora A, Evans LS, Bahary N, Soori GS, Eakle J, Robertson JM, Moore DF Jr, Mullane MR, Marchello BT, Ward PJ, Wozniak TF, Roh MS, Yothers G, Wolmark N: Capecitabine and oxaliplatin in the preoperative multimodality treatment of rectal ancer: surgical end points from National Surgical Adjuvant Breast and Bowel Project Trial R-04. J Clin Oncol 2014, 32(18):1927-1934.

33. De Las Heras M, Arias F, Del Moral-Avila R, Gómez-Millán J, Jiménez E, Wals A, Tisaire $J$, Alcantara MA: Multicenter phase II clinical trial of preoperative capecitabine with concurrent radiotherapy in patients with locally advanced rectal cáncer. ClinTrans/ Oncol 2013, 15:294-299.

34. MacLeod A, Branch A, Cassidy J, McDonald A, Mohammed N, MacDonald L: A nurse-/pharmacy-led capecitabine clinic for colorectal cancer: results of a prospective audit and retrospective survey of patient experiences. Eur J Oncol Nurs 2007, 11(3):247-254.

35. Van Hoeve J, De Munck L, Otter R, De Vries J, Siesling S: Quality improvement by implementing an integrated oncological care pathway for breast cancer patients. Breast 2014, 23(4):364-370.

36. Joye I, Lambrecht M, Jegou D, Hortobágyi E, Scalliet P, Haustermans K: Does a central review platform improve the quality of radiotherapy for rectal cancer? Results of national quality assurance project. Radiother Oncol 2014, 111(3):400-405.

\section{doi:10.1186/s13014-014-0260-0}

Cite this article as: Arenas et al:: Quality assurance in radiotherapy: analysis of the causes of not starting or early radiotherapy withdrawal. Radiation Oncology 2014 9:260.

\section{Submit your next manuscript to BioMed Central and take full advantage of:}

- Convenient online submission

- Thorough peer review

- No space constraints or color figure charges

- Immediate publication on acceptance

- Inclusion in PubMed, CAS, Scopus and Google Scholar

- Research which is freely available for redistribution 